\title{
REMOTE SENSING DATA IN MUNICIPAL GOVERNMENT
}

\author{
Jaroslav Nýdrle 1,2
}

1. CTU in Prague, Faculty of Civil Engineering, Department of Geomatics, Prague, Thákurova 7, Czech Republic, jaroslav.nydrle@fsv.cvut.cz

2. Jan Evangelista Purkyně University in Ústí nad Labem, Faculty of Environment, Department of Geoinformatics, Ústí nad Labem, Pasteurova 3632/15, Czech Republic

\begin{abstract}
This article focuses on the issue of using data obtained through remote sensing methods in the administrative district of the municipality with extended powers of Liberec (the Czech Republic). The first part of the article discusses the question of using Earth remote sensing data for city agendas in general. Then, it presents a questionnaire, created for evaluating the needs of the Liberec municipality. This questionnaire, focusing on the use of remotely sensed data, was created on the basis of a review of relevant literature. Based on the results of the questionnaire, thefollowing spatial information requirements were chosen to be addressed: land surface temperature map - LST (Landsat 8), vegetation index - NDVI (Sentinel 2, Planet Scope), normalized difference water index - NDWI, NDWI 2 (Sentinel 2), normalized difference built-up index - NDBI (Sentinel 2). All data obtained during the creation of this study have become part of the database of the Urban Planning and GIS Department and are available to employees of the City of Liberec.
\end{abstract}

\section{KEYWORDS}

Satellite, Landsat 8, Planet Scope, Sentinel 2, Remote sensing, LST, NDVI, NDWI, NDBI

\section{INTRODUCTION}

\section{Literature Review}

Satellite data are a type of remotely sensed data [1]. The main advantage of satellite data over other types of remotely sensed data, is the ability to swipe a large area in a fairly high spatial resolution (for example, Sentinel1: up to $5 \mathrm{~m}$ / pixel, Sentinel 2: $10 \mathrm{~m} /$ pixel), another advantage is the frequency of data acquisitionin our latitudes (Sentinel 2A, 2B - once every 5 days) [2]. Satellite data is also very often extended by so-called spectral bands, which are called multispectral data. Information about the specific reflectivity curve of the monitored material on planet Earth allows one to extract various types of information from multispectral data (for example water, greenery, rocks) [3].

To date, Landsat has extended operations to 8 satellites, including Landsat 9, launched in September 2021. (The seeming contradiction in numbers is due to the fact that although they have launched 9 satellites Landsat 6 was destroyed at launch.) These satellites, propelled to orbit by the USS NASA and the USGS, supply data to the satellite data archive. Data from these satellites are freely available after registration and are frequently used for purposes of research. Their use is enhanced by the use of time series and the resulting possibility of analyzing changes in the landscape over time. S. Ahmadi et al, for example, use Landsat 4, Landsat 5 (data from 2001, 2008) and Landsat 8 (data from 2018) in their study to study drought [1]. Based on a combination of spectral bands, they calculate, amongst others, the NDVI vegetation index, which monitorsdrought successfully using data from different years.

J. P. Mondejar and A. F. Tongco have used Landsat 8 data to obtain spatial information about the location of watercourses and water bodies [4]. They have proven that thesemethods are suitable 
for surface water mapping. The most usable zone for exploring water bodies, in their view, is NIR, as it captures the largest difference in reflectance values between water and solid earth structures (it has better results in this respect than NDWI and MNDWI water indices). Therefore, Mondejar and Tongco's study has confirmed that remote sensing can extract or define bodies of water very quickly, repeatedly and accurately [4]. A problem may, however, arise when attempting to map small watercourses in wooded areas. In such cases, it is advisable to supplementthe mapping with a digital model of relief, or a temperature map created using the TIRS (thermal infrared sensor) of the Landsat 8 band (assuming a different temperature of water and its surroundings).

Further, Marcof and Statescu have used Landsat 8 data to examine the relationships between LST (Earth surface temperature), NDBI (standardized building index) and NDVI (vegetation index) [3]. The results of this work have confirmed a strong linear relationship between LST and NDBI, which suggests that in urban areas the surface temperature depends on the materials used (generally throughout the territory of land use and related landscape cover). The relationship between LST and NDVI, however, has been found to vary by season.

Other freely available satellite data is accessible through the European Union's Copernicus program. Here, we focus only on Sentinel-2 data. The Sentinel-2 mission is designed to collect data suitable for research on landscape use and for mapping changes in the landscape (according to the Copernicus program's Czech website). This is multispectral data composed of thirteen bands. Wong, M.F. F. et al. have based their research on Sentinel-2 data to calculatethe NDVI in the Pearl Delta region. Their article compares the resulting layer of filtered vegetation with high-resolution data from Google Maps RGB [5]. The data correlation reaches 0.97 , confirming thehigh quality of Sentinel-2 data.

J. Radax et al. compare the usability of Landsat 8 and Sentinel-2 data in mappinglandscape usage [6]. The authors acknowledge the better spatial resolution of the Sentinel-2 sensor compared to Landsat-8 and conclude that Sentinel-2 data is already usable for mapping small watercourses with a width of about $5 \mathrm{~m}$ and strips of vegetation in the city. At the same time, they add that it would be appropriate to modify or supplement certain zones in the event of another similarmission, and also conclude that the progressively more detailed spatial resolution and subsequent interpretation of data has been moving the boundaries of the research and understanding of naturalprocesses. Kaplan G. et al. has also discussed the mapping of heat islands through the use of satellite data [7].

Other operators that provide multispectral satellite data include, for example, Planet Labs Inc.'s satellite system that includes the following satellite groups: Planet Scope (175 Dove satellites), RapidEye (5 satellites), Skysat (13 satellites). Planet Labs Inc. data. grant free use of data for study purposes, and it was, indeed, possible to obtain a limited amount of data from their satellites. Other commercial projects working for the acquisition of satellite multispectral data are DigitalGlobe (WorldView, Ikonos, QuickBird, Geoeye-1); AIRBUS Defence and Space (Pléiades, SPOT). This data, however, is understandably used to a lesser extent in science than data freely available (Landsat, Sentinel).

Satellite data has significant information power in terms of longer-term earth observation by the same (data archives) or very similar methods (sensors). In fact, in scientific studies, a combination of different satellite data is very frequently used. An example of the use of satellite data archives and the combination of imagery from different satellites is, for example, the work of MacLachlan, A. et al., which explores urbanization and the growth of the city of Perth in Australia through images from Landsat satellites (Landsat 5 TM, Landsat 7 ETM+, Landsat 8 OLI) [2]. The authors of the study have calculated that the spatial range of the city of Perth increased by $45 \%$ (320 sq km) between 1990 and 2015.

\section{The Context of the Research}

This article discusses the possibilities of using remotely sensed data in city administration, and, in particular, public administration. The discussed research was originally executed for the Municipality of Liberec (the Czech Republic). Up to this point, the Municipality of Liberec tended to use remotely sensed data only to a limited extent. Among the data previously used were orthophotos 
of the Czech Surveying Office as well as those of the State Administration of Land Surveying and Cadastre, available through the WMS service. Other data used by city workers were in the form of orthophotospurchased to order (also via WMS). Figure 1 shows the location of the area.

The city of Liberec has access to data on watercourses and water bodies through the use of Digital Base of Water Management Data, and small watercourses have also been mapped as part of the processing of the Territorial Landscape Study of Liberec Municipality's Administrative District with Extended Powers. Ä possible use of the satellite method, similarly to those outlined above, can be thus seen in refiningand, if possible, supplementing existing databases with missing watercourses and water areas.

This is especially so since the city of Liberec, before the present research, did not have such interpreted data, yet this type of data could be a suitable source of complementary information aiding the activities and work ofthe Department of Greenery and Public Space Administration to plan the planting and maintenanceof existing greenery. This issue is also related to so-called urban heat islands (UHI), whose scientificmapping with clear and understandably visualized results in Liberec is also lacking.

The reason Sentinel-2 data is usable for the city of Liberec is that the city does not yet have a green passport. At the same time, the detail of data thus accessible does not provide a high enough resolution to create a green passport. Nevertheless, using this data could at least serve as abasis for mapping and monitoring the development of vegetation in the city.

\section{RESEARCH AIMS}

The aim of this article is thus to assess the possibility of using remotely sensed data on the territory under the auspices of the Municipality of Liberec. The statutory city of Liberec is a city with extended powers and therefore also manages the surrounding municipalities in some agendas (e.g. environmental protection, spatial planning), therefore the focus of research is not only the city of Liberec, but also the surrounding municipalities (28 municipalities altogether including that of the city of Liberec itself.

Based on the processing of the above survey of the possibilities of using remotely sensed data, a questionnaire was prepared on the use of spatial data and on the potential information needs of the municipality's various departments and organizations (this latter aspect was formulated in a general manner, since many workers have had no idea what remote sensing is). The results of the questionnaire were then used to select the appropriate remote sensing data for earth analysis. The main aim of the research was to confirm the applicability of DPZ data in the working environment of the administrative district of the municipality. A selection of data from satellites would be thus used to fulfill the identified needs of city workers and urban organizations.

One of the main challenges of the research was presented by the implementation of the resulting layers in the strategic documents of the city of Liberec (Adaptation of the City of Liberec to climate change, Manual of public space of the city of Liberec), which are still in the process of creation or finalization.

\section{DATA AND RESEARCH METHODS}

\section{Area of interest}

The research area is defined by the administrative district of the municipality with extended powers Liberec (SO ORP Liberec). Liberec City Hall (because it is a municipality with extended powers) is in charge of the data for all 28 municipalities. Figure 1 visualizes the administered area of SO ORP Liberec in the context of the Liberec region and indicates its location within Europe. SO ORP Liberec is located in the north of the Czech Republic and borders the northern part of The Federal Republic of Germany and the Republic of Poland. 


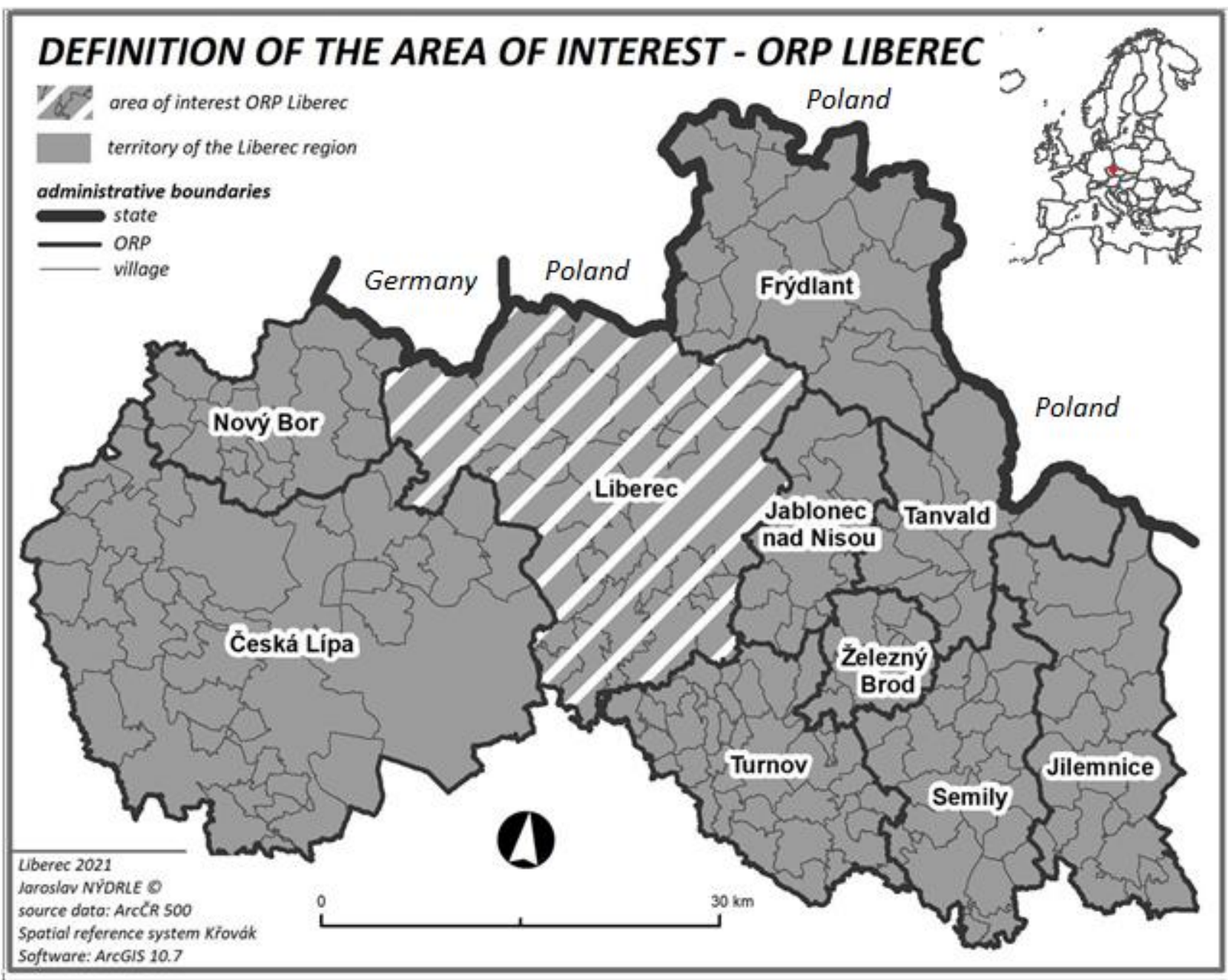

Fig. 1 - Definition of the area of interest - ORP Liberec

\section{Questionnaire}

As part of the questionnaire survey, all heads of individual departments of the City of Liberec (Department of Tourism, Culture and Sports; Department of Transport; Department of ecology and public space; Department of Economics; City Architecture Office; Mayor's Office Department; Control and Internal Audit Department; Property Management Department; Legal Department and public procurement; Department of Education and Social Affairs; Department of Building Authority; Department of Social Welfare; Department of Administration and Trade; Public Property Management Department; Department of Strategic Development and Subsidies; Spatial Planning Department; Department of Home Affairs; Department of the Environment) and selected contributory organizations that are likely to use spatial data (Liberec IT services; Urban forests Liberec) were asked to fill in a questionnaire. The questions in this questionnaire were previously consulted with the staff of the UAP and GIS departments.

As part of the questionnaire survey, 18 departments of the City of Liberec and 2 contributory organizations (Liberec IT services; Urban forests Liberec) were contacted. Thanks to the support of the Secretary of the City of Liberec, we managed to obtain a $100 \%$ feedback on the questionnaires. Of the 20 subjects surveyed, $75 \%$ of the respondents use spatial data, which is exactly 15 respondents (heads of individual departments consulted the answers with their subordinates). On the contrary, $25 \%$ of the answers were negative, i.e. 5 respondents (subjects) do not use spatial 
data. We can therefore say that spatial data are widely used at the City of Liberec and municipal organizations and there is great potential for further development.

\section{Satellite imagery}

With the aid of the questionnaire survey, key information needs were selected, which were then matched with the possibilities of using the available data, as identified above on the basis of the literature. In this manner, freely available satellite data from the US Landsat program (specifically data from the Landsat satellite $8-30$ meters / pixel), as well as from the European satellite program Copernicus (consistently data from the sentinel $2-10$ meters / pixel), became the main source of data.

In addition, as a result of a successful correspondence with the American company Planet and my inclusion in their Science Program Education and Research, images ofPlanet Scope satellites that scan the earth's surface at a frequency of 5.5 days above the same place could be obtained. Planet Scope's data is $3 \mathrm{~m}$ pixel in resolution and has a multispectral spectral resolution (RGB + NIR $=4$ band), thanks to the nearby infrared band, the Planet Scope satellites (represented by 175Dove satellites) could be used to analyze vegetation and the combination of bands in the grid calculator could create an NDVI index.

In terms of supplementary data available for the territory of the SO ORP Liberec, relevant data from any Landsat mission (1-9) is worth mentioning, as well as that of the European program Copernicus Sentinel 1, Sentinel 3, Sentinel 5P. What makes these information sources especially valuable for Liberec city workers is the fact that this additional data is available at all times and, if necessary, their availability is ensured at a moment's notice, i.e. a smooth download from the hub of the European Copernicus program. Landsat 8, Sentinel 2 and Planet Scope satellite data were thus also used in this work.

The main reason for using a single data set instead of data from longer time span sprung from the specific requests made by the Municipality of Liberec. They requested the most up-to-date data available since they intended to use them as the basis for creating such documents as the city's green passport, public space manual, or the layer of surface waters. Thus, the latest momentary data was favored over an average calculated from a wider sample of data. As a result, the latest available images with no cloud cover were used (e.g. in the case of temperatures on a hot summer day).

In addition, in the case of surface temperature, the research was aimed only at mapping thermal islands, and thus it was appropriate to use the latest usable image of the hottest summer day without cloud cover. The use of an average value could have led to biased results due to a range of factors (e.g. construction work, changes in the use of land).

\section{Related Works}

In their 1974 study, Rouse, J. et al., used the Normalized Difference vegetation index (NDVI) for the first time on Landsat 1 satellite data [8]. Rouse J. was the director of the Earth Remote Sensing Center at Texas A\&M University at the time. The NDVI vegetation index is still widely used in the basic form, but also in other modifications.

The NDBI constructionindex was first used in 2003 in the work "Using the normalized index of difference created in the automatic mapping of urban areas from TM images" [9]. Currently, for example, Macarof, P. et al. work on comparing NDVI and NDBI as a factor in defining heat islands in cities [3]. Kaplan G. at al. use the same data processing method for the extraction of thermal islands information (LST - land surface temperature) in Skopje (case study 2013 - 2017) [7]. They alsonormalize the data to the NDVI vegetation index. In their 2017 work, Macarof P. and Statescu F. compare the relationship between the surface temperature of Landsat 8 in comparison with the NDVIvegetation index and the NDBI construction index [3].

The normalized index of water content on the Earth's surface has two variants reported in the literature [10]. The first variant is: NDWI $=($ Xgreen - Xnir $) /($ Xgreen + Xnir $)$. In this form, satellites with 
anear infrared band (NIR) are usable (Landsat 8, Sentinel 2 and Planet Scope). The index of water content on the Earth's surface was used, for example, in 1996 by McFeeters S. K. in his work in defining the layer of uncovered water bodies [10]. Hafizi, H. et al. use NDWI to obtain an NDWI surface moisture layer, from which a layer of water surfaces can be obtained by categorization and conversion to a vector in their work:"Evaluation of approaches to the extraction of water bodies based on objects using Landsat-8 images" [11]. The fact that the NDWI index is still used in 2020 confirms that the index is still current and scientifically relevant.

\section{Analyzed indices}

Based on the sources discussed above, it is possible to conclude that the relationship between LST and NDBI (normalized difference built-up index) is a strong linear relationship. When examining the relationship between the vegetation index and surface temperature, it was found that the relationship is very dependent on the season. It can therefore be argued that the NDBI construction index is a fairly accurate indicator of the effects of urban heat islands in the city.

For the purposes of mapping of water surfaces, a normalized index of water content based on Sentinel 2 data ( 10 meters / pixel) was used for data processing for the entire SO ORP, because it has sufficient spatialresolution for regional planning (Planet Scope data - 3 meters / pixel is more suitable for the analysis of the city of Liberec).

Sentinel 2 is a multispectral satellite of the European program Copernicus. For comparison, a layer of Landsat 8 satellite data was made using the same methodological procedure. The resulting data would be available as a source material for the Department of the Environment. A new phenomenon of territorial analytical data is (after the amendment to the Building Act, which has been in force since 1 January 2018) phenomenon No. 46A - surface water used for bathing. As a first step in determining said areas, it is convenient to analyze the Sentinel 2 data to obtain an NDWI surface moisture layer, from which a layer of water surfaces can be obtained by categorization and conversion to a vector.

The construction index can be calculated by raster algebra in any GIS program environment fromthe data of the Landsat 8 satellite or the Sentinel 2 satellite. In the previous chapter, it was confirmed that a larger scale is a better option for the needs of the city of Liberec. It is true that the identification ofbuildings using the Build-up index would be possible using Landsat 8 , where a resolution of 30 meters / pixel can also distinguish most buildings, but since data from Sentinel 2 with a resolution of 10 meters / pixel is also available, they are naturally preferable for the user.

Build-up Index (NDBI), or construction index is a usable form of data for the Office of Architecture of the City of Liberec, or for the Department of Spatial Planning (rather as overview data, otherwise they have more detailed data from the spatial planning process, but those are sometimes out of date and this provides further potential for use). Alternatively, it is possible to consider the use of the methodology in the planned update of the map Land use / Land cover (Territorial study of the landscape SO ORP Liberec).

The NDBI construction index was calculated from Sentinel 2 satellite data. It was important, as always, to select suitable data, which could not contain more than $10 \%$ cloud cover (ideally none) and had to cover the entire territory. The calculation of the NDBI index in the raster calculator looks like this NDBI = SWIR (band 11) - NIR (Band 8) / SWIR (band 11) + NIR (band 8).

NDVI works on the principle of vegetation display based on the difference between the near infrared and red bands. It is calculated according to the relation: NDVI = (NIR - RED) / (NIR + RED). The physiological state (higher chlorophyll content) of green plants absorbs red light (RED). The cellular structure of vegetation, on the other hand, reflects the NIR (near infrared spectrum). The data are again processed using raster algebra in the ArcGIS program environment.

\section{Processing software}

In the processing of satellite multispectral data (Landsat 8, Sentinel 2, Planet Scope), raster algebra tools were used. The analyses were carried out in ArcGIS 10.8. Other GIS software can also 
be used. The reason I chose ArcGIS 10.8 is that it is user friendly. Raster algebra allows for the calculation of indices (NDVI, NDWI, LST). The calculated indices represent the mathematical ratio of bands from the data of a particular satellite.

\section{RESULTS}

\section{Map of Surface Temperature and Delimitation of Heat Islands in the Administrative District of the Municipality with Extended Scope of Liberec}

The data from the Landsat 8 satellite is multispectral data with Thermal Infrared Sensor (TIRS). The data has the aforementioned TIRS band, which allows the processor to extract surface temperature information using a raster algebra. We are here limited by the frequency of Landsat 8's overflight, which is every 16 days. Current weather conditions (especially cloud cover) further limit its use.

Tab. 1 - Area of individual surface temperature categories, data source: calculated from Landsat 8

\begin{tabular}{|c|r|}
\hline \multicolumn{2}{|c|}{ Area of individual surface temperature categories } \\
\hline$\left[{ }^{\circ} \mathrm{C}\right]$ & {$\left[\mathrm{km}^{2}\right]$} \\
\hline less than 26 & 8.15 \\
\hline $26.1-28$ & 145.31 \\
\hline $28.1-30$ & 168.2 \\
\hline $30.1-32$ & 138.53 \\
\hline $32.1-34$ & 84.24 \\
\hline $34.1-36$ & 28.87 \\
\hline 36.1 and over (maximum 44.5) & 5.15 \\
\hline Area SO ORP Liberec (total) & 578.45 \\
\hline
\end{tabular}




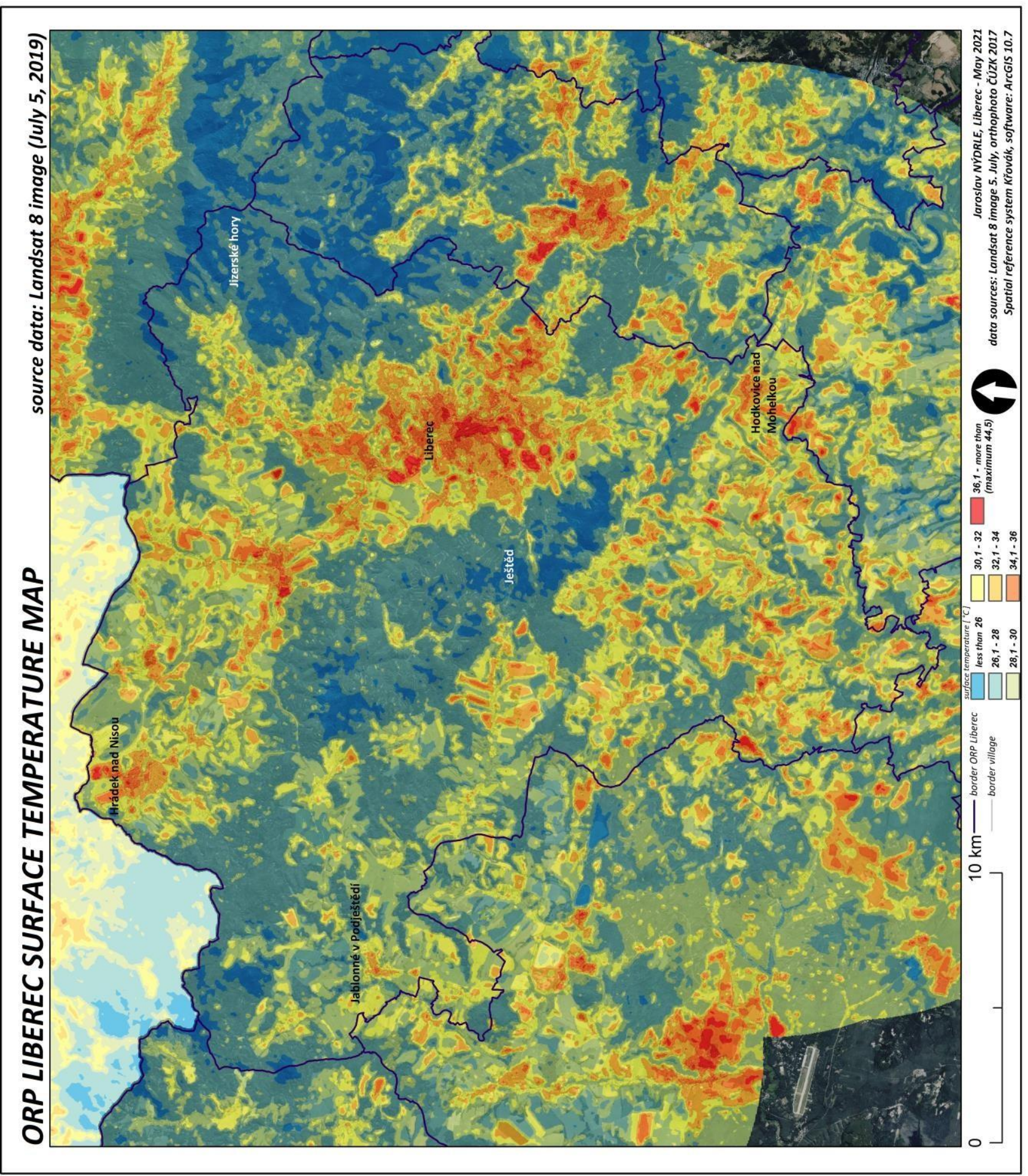

Fig. 2 - ORP Liberec land surface temperature map, data source: Landsat 8 image 5 July 2019

The image from 5 July 2019 was selected for the delimitation of the heat islands, when the highest surface temperature was identified (high temperature difference in the area of the entire image - high amplitude). Figure 2 visualizes a map of the surface temperature of SO ORP Liberec from 5 July 2019. The data was categorized into 7 intervals, so that the boundaries of heat islands in municipalities are more clearly defined. The map shows that the thermal islands are almost identical in boundaries to the buildings and built-up areas. By interpreting the map, we find that the heat islands in the Administrative District of the municipality with extended powers of Liberec are the 
built-up centers of municipalities (localities of the warmest category 36.1 and more with a peak of $44.5^{\circ} \mathrm{C}$ ). Other areas that are in the intervals of $34.1-36^{\circ} \mathrm{C}$ and $32.1-34{ }^{\circ} \mathrm{C}$ are localities with exposed substrate, burned meadows, areas with arable land, and roads. Other categories 30, 1 $32{ }^{\circ} \mathrm{C}$ and $28.1-30{ }^{\circ} \mathrm{C}$ are represented from the point of view of land use by meadows and places with small vegetation. The coldest two categories $26.1-28{ }^{\circ} \mathrm{C}$ and less than $26^{\circ} \mathrm{C}$ are represented by forests and water bodies. The most extensive localities with low temperatures are the JeštědKozákov ridge (Karlov Beech Forest) and the foothills of the Jizera Mountains (Jizera Mountains Beech Forest). Areas are shown in Table 1.

From the information obtained, it is clear that the surface temperature is a reflection of land use. This fact is a guide for us in planning adaptation as well as mitigation measures in city centers. The current trend of implementing greenery, water features, retention reservoirs, dry polders, but also the revitalization of watercourses and generally a return to a near-natural state, is important for mitigating the effects of climate change in urban centers. However, it is also important to deal with large soil blocks, which we should supplement with drawbridges, woods and retention reservoirs and thus reduce their area and reduce the surface temperature there as well (places will be more suitable for animal life and biodiversity will increase).

\section{Map of the Standardized Water Index of the Administrative District of the Municipality with Extended Powers of Liberec}

In Figure 3 visualizations of water content on the Earth's surface in SO ORP Liberec can be seen.There is a comparison of results from Sentinel 2 - 10 meters / pixel and Landsat 8 - 20 meters / pixel(Sentinel 2 image from June 30, 2019 and image from Landsat 8 satellite from July 5, 2019). In the section at the bottom left, where the Harcov Reservoir can be seen, the importance of raster resolution is clearly demonstrable in the extraction of spatial information. From the Sentinel 2 satellite (10 meters / pixel) we can obtain a relatively accurate estimate of the water surface boundary. In contrast, in the image from Landsat 8 (30 meters / pixel) we can obtain a defined water area only very approximately. In the cut-out on the right we can see the Harcov Reservoir again. The data were created by raster algebra from the bands of the Landsat 8 satellite. The resulting raster is based on a Landsat resolution of 8 - 30 meters / pixel. Landsat 8 is therefore more suitable for regional planning or survey analysis. In contrast, Sentinel 2 with 10 meters is sufficient (it is also possible to use Planet Scope, but the detail of the defined water areas is sufficient). From the obtained data visualized in Figure 3, it is apparent that the calculation of NDWI according to this algorithm does not completely display surface moisture. NDWI in the variant with NIR and GREEN band is suitablefor obtaining a layer with water surfaces. 
Article no. 73

CIVIL

ENGINEERING

JOURNAL

THE CIVIL ENGINEERING JOURNAL 4-2021

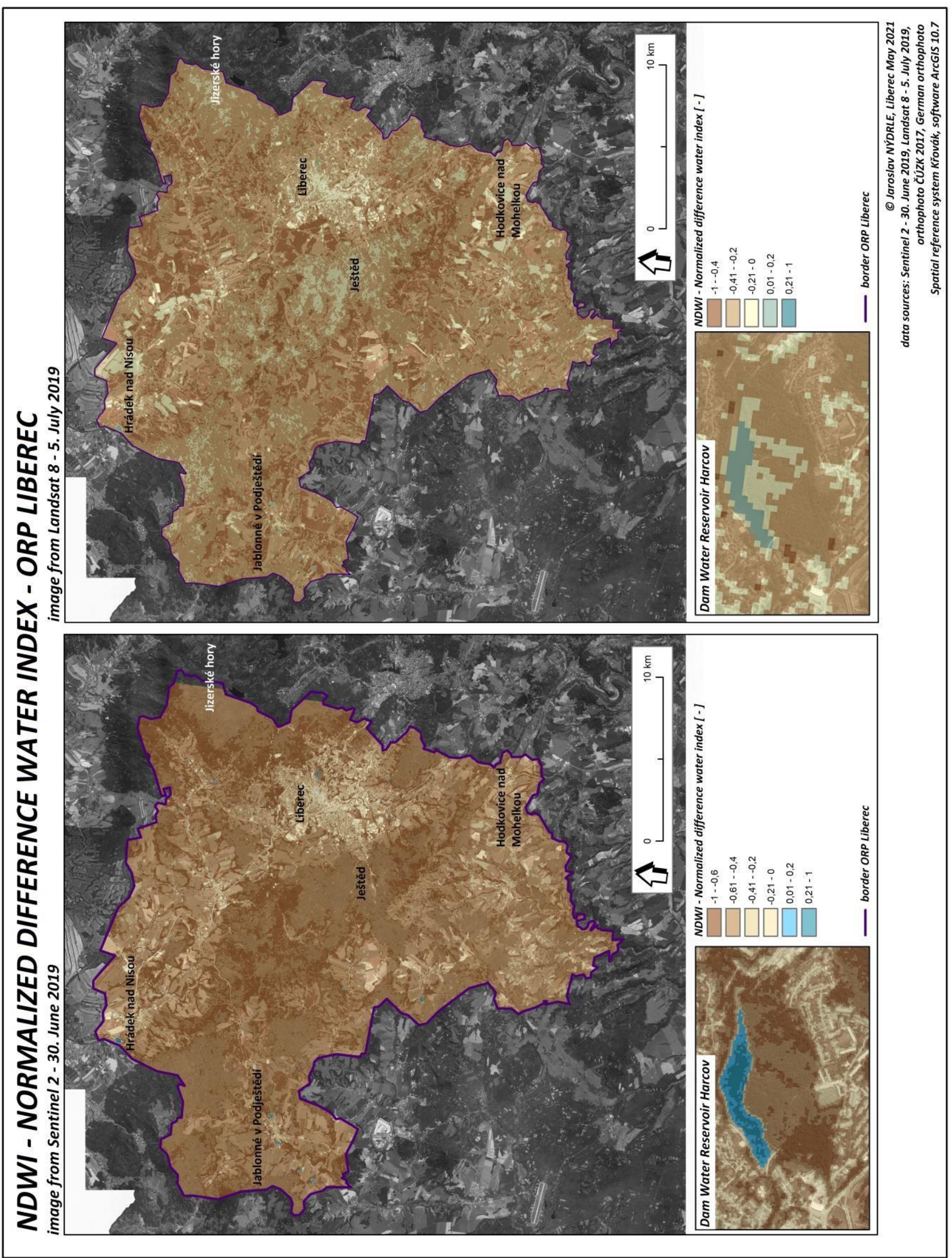

Fig. 3 - NDWI - Normalized difference water index - ORP Liberec, source data: Sentinel 2 - 30. June 2019, Landsat 8 - 5 July 2019. 


\section{Map of the Normalized Build-Up Index (NDBI) of a Municipality with Extended Powers in Liberec}

Figure 4 visualizes the construction index data from images from the Sentinel 2 satellite from 5 June 2016 and from 30 June 2019. The NDBI construction index is a tool that allows for the visualization of the growth of urban development. However, it is more important in places where we do not have better data (Sentinel 2 - 10 meters pixel). In our case, the city has an overview of the construction within the spatial planning process. The potential is in detecting illegal structures (at a time when there will be a better resolution of the new satellite and the process will be automated). From the cut-outs around the Train Station in Liberec, it is clear that the resulting data do not differ significantly. In the peripheral parts of the city, the color is increasing (growth of buildings). The analysis is based on a similar value of the area without vegetation (arable land) as the area with buildings, which is its limit.

The city of Liberec has more accurate data on the location of individual buildings within the spatial planning process (Cadastre of Real Estate of the Czech Republic, RÚlAN - register of territorial identification, addresses and real estate, Land use / land cover mapping), but there is a problem with their timeliness (and also with illegal buildings). If the algorithm for extracting data from multispectral remote sensing data (in the future hyperspectral data) could be improved, this process (inspections of illegal structures) could be performed regularly by automatic inspection using (for example) a difference assembly with approved and unapproved structures. This would be a great contribution to the process of controlling illegal construction, which is objectively happening in the area today. The way in the right direction will also be to increase the spatial resolution of the satellites (SkySat satellites already paid today - 0.8 meters / pixel). 
Article no. 73

CIVIL

ENGINEERING

JOURNAL

THE CIVIL ENGINEERING JOURNAL 4-2021

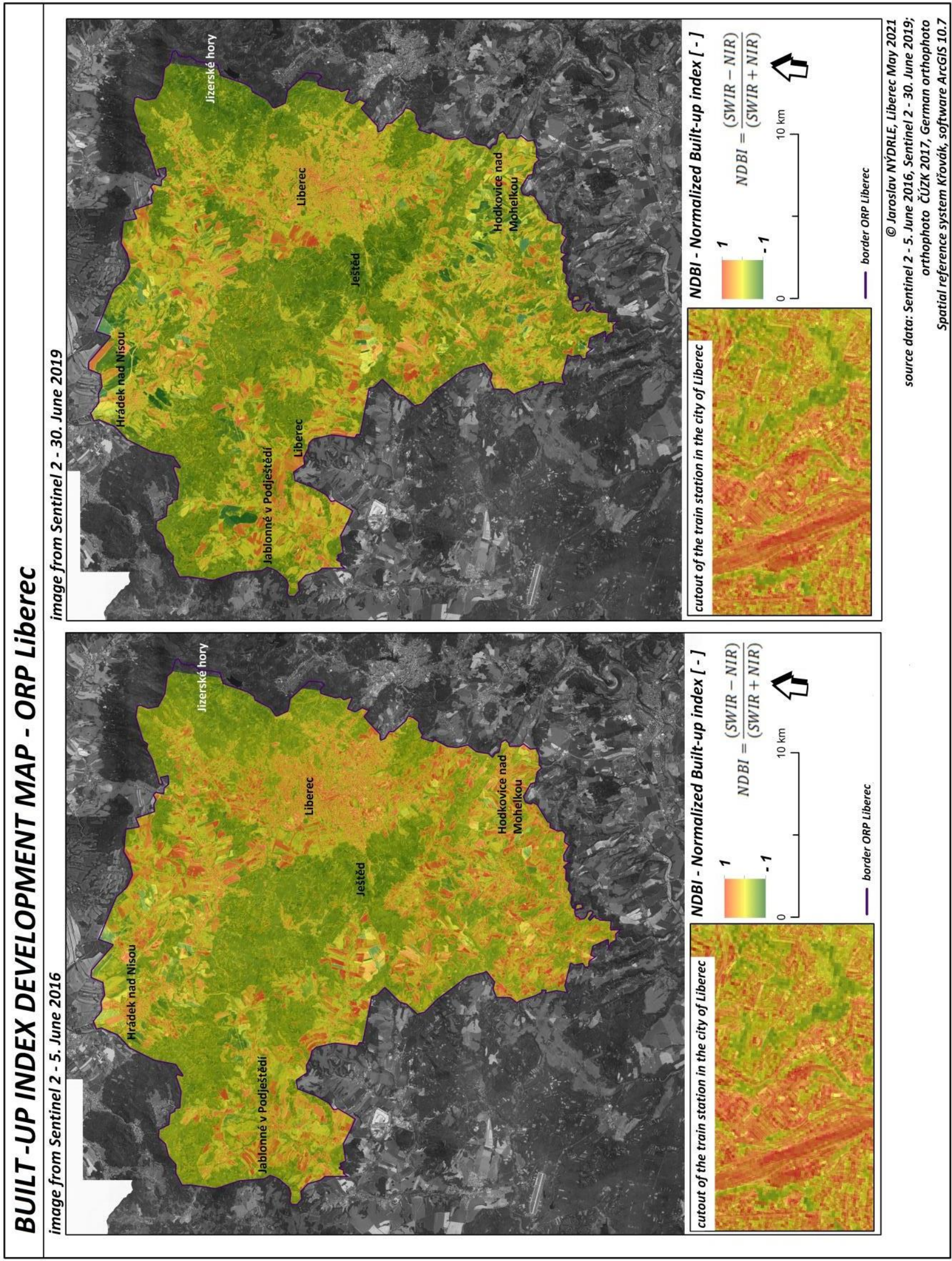

Fig. 4 - Built-up index development map - ORP Liberec, source data: Sentinel 2 - 5. June 2016, Sentinel 2 - 30 June 2019 


\section{Map of the Normalized Vegetation Index (NDVI) of a Municipality with Extended Powers in Liberec}

The data accessible for this research project has the necessary bands for the calculation in the following resolutions: Landsat 8 (30 meters / pixel); Sentinel 2 (10 meters / pixel) and Planet Scope (3 meters / pixel). For the most current situation, as a basis for mapping greenery for the purposes of green passport in the city of Liberec, the most detailed possible Planet Scope data would be used, and the obtained results would be available to the Department of Ecology and Public Space in Green Management in Liberec, green mapping (for green passport), the Office of Architecture of Liberec as a basis for the Public Space Manual of Liberec and also for the UAP and GIS Department as part of the Adaptation Strategy to change the climate of the city of Liberec.

Because the green passport's development was handled by the Department of Ecology and Public Space in the spring / summer 2020 period, the most recent image of the Planet Scope satellite from May 2020 was selected. Planet Scope is represented by several satellites (Dove) that scan the Earth's surface parallel to each other at one time, it is thus necessary to create a raster mosaic for the needs of analysis and then to analyze the data. Processing the data acquired from Planet Scope is therefore more time consuming, mainly as a result of the higher resolution. Visualization of the obtained NDVI vegetation index details in Figure 5. 
Article no. 73

CIVIL

ENGINEERING

JOURNAL

THE CIVIL ENGINEERING JOURNAL 4-2021

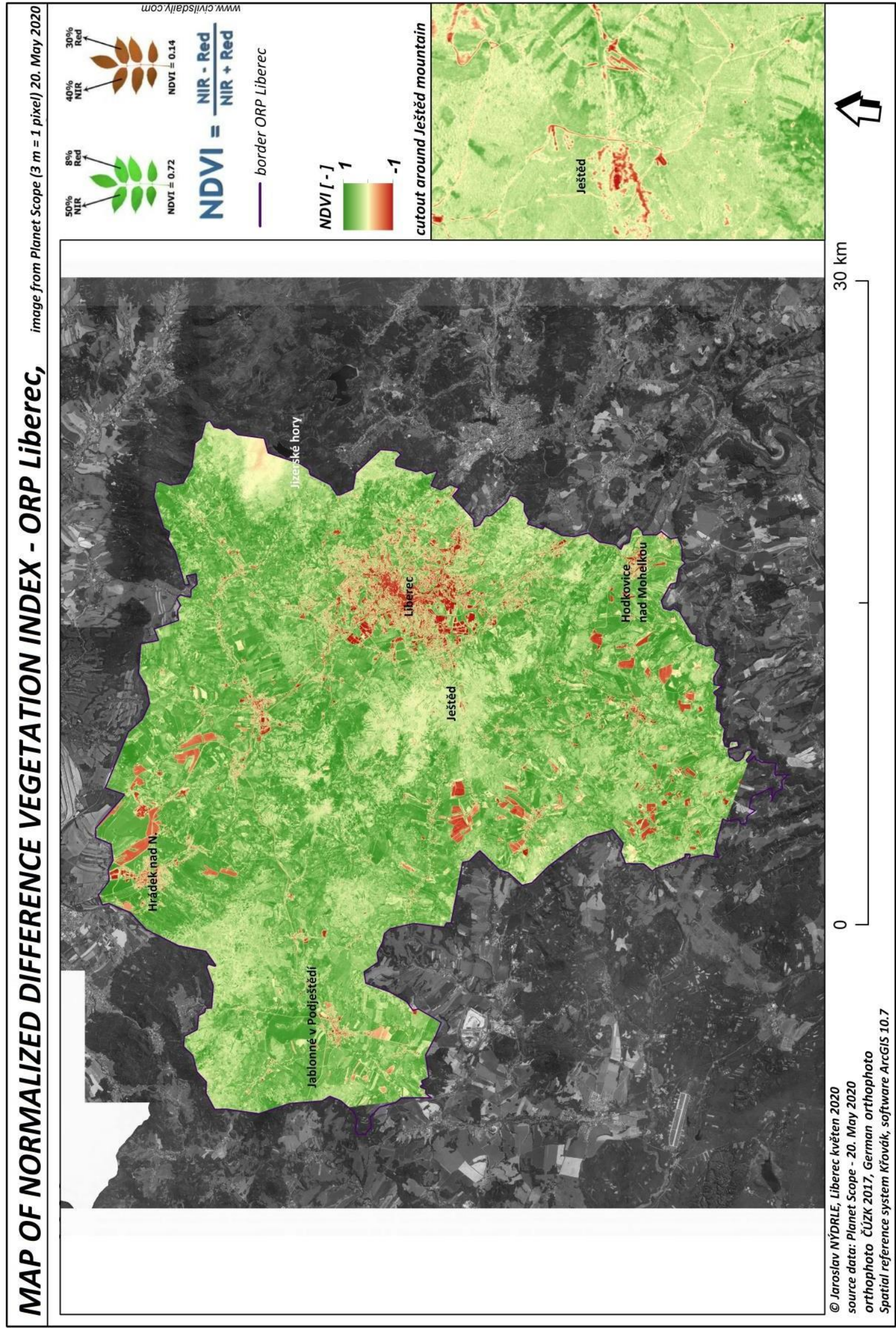

Fig. 5 - Map of normalized difference vegetation index - ORP Liberec, source data: Planet Scope 


\section{DISCUSSION}

From the available data of the Landsat 8 satellite, surface temperature maps for the city of Liberec were prepared using raster algebra in the ArcGIS program environment. The data were processed for the entire area of interest of SO ORP Liberec (28 municipalities). The method of obtaining surface temperature information was applied to the data. The image from 5 July 2019 was selected for the identification of heat islands, because it has large differences (high amplitude) in temperature between the urban environment and close to nature. The image was classified into 7 temperature categories, of which the highest $36^{\circ} \mathrm{C}$ - and more (maximum $44.5^{\circ} \mathrm{C}$ ) represents the city centers with the highest temperature (industrial zones, squares, parking lots - places with the lowest percentage of vegetation). The hypothesis in the introduction of the article was the assumption that the warmest places will be just the mentioned type (paved surfaces, parking lots, etc.). In this way, the areas of the heat islands were defined. In the second category, the areas of $34.1-36{ }^{\circ} \mathrm{C}$, are less urbanized places in the centers, which already contain greenery and water features, but in minimal form. Other categories are simply used in a state closer to a natural state (places with arable land or exposed substrate also show a high temperature). Areas of individual categories were also calculated, the sum of which is in accordance with the area of SO ORP Liberec $\left(578.4 \mathrm{~km}^{2}\right)$. The same method of obtaining information on thesurface temperature of the Earth is used by Kaplan, G. et al. in their work from 2018, where they apply the methodology to the city of Skopje (examination of the surface temperature of the city in theyears 2013 - 2017) [4]. All data became part of the data warehouse of the UAP and GIS Department.

The potential of surface temperature data may be seen in the possibility of using a thermal sensor ona UAV (drone) in problem areas in city centers, but also in natural areas where it is necessary to identify the problem. Processing the surface temperature map from Landsat 8 data can serve as a tool for identifying problem areas that can be further mapped via UAV with a higher thermal imager resolution (Landsat 8 - 30 meters / pixel; UAV thermal imager 0.5 - 2 meters / pixel $\checkmark$ depending on the flight altitude).

Multispectral data from the Sentinel 2 satellite with a spatial resolution of 10 meters / pixel were used to calculate the NDWI water index in the variant reported in the literature as follows: NDWI = (Xgreen - Xnir) / (Xgreen + Xnir). The resulting raster (created using raster algebra) was classified and converted to a vector. A category containing water bodies was selected from the vector and exportedto a separate layer. In this way, the data applicable to the territorial analytical data (46A marking of the phenomenon in the official geodatabase) surface water bathing phenomenon were generated. It is worth mentioning that data from the Planet Scope satellite with ahigher resolution (3 meters / pixel) can also be used for this index. The NDWI index in the variant with GREEN and NIR band was used by S. K. McFeeters already in 1996 in his work in defining thelayer of uncovered water areas [10].

The potential of multispectral data in satellite images can be generally seen in increasing their resolution and flight frequency (as well as in improving image interpretation methods). In the future also in the $5 \mathrm{G}$ network and the "world internet". In the case of usability of the image (cloudless conditions), it could be possible to immediately apply remote sensing methods using scripts and, thanks to automated interpretation, to immediately know information about the state of the earth's surface. All this will be usable in case of sudden changes, disasters managements, calamities, etc.

The normalized difference built-up index(NDBI) was interpreted using raster algebra based on the multispectral data from the Sentinel 2 satellite. NDBI highlights urban areas where shortwave infrared(SWIR) reflectivity is usually higher than near infrared (NIR) areas. The construction index was developed for use with the Landsat TM 5 and 4 bands. However, the index works with all multispectral data that contains the SWIR and NIR bands. The NDBI construction index was first used in 2003 in the work "Using the normalized index of difference created in the automatic mapping of urban areas from TM images" Zha, Y. et al. [9].

The last multispectral data analyzed are again images of the Sentinel 2 satellite for the purpose of analyzing the physiological state of vegetation. The index works with RED and NIR bands. The index relationship is as follows: NDVI = (NIR - RED) / (NIR + RED). The normalized difference 
vegetation index (NDVI) is a graphical indicator usable over Earth remote sensing data that can be used to assess whether objects on the Earth's surface contain vegetation in physiologically good condition. In the literature, the NDVI index was first used by Rouse, J. W. et al.already in 1974 (Monitoring of vegetation systems in large plains using ERTS) [8]. The index is used inthe basic modification and in various others to this day. Thanks to technological development, this index can also be used with data in a more detailed resolution (Planet Scope 3 meters / pixel). PlanetScope data were used to analyze the current state of vegetation in the city of Liberec for the purposesof its mapping.

\section{CONCLUSION}

Based on the needs (questionnaire survey and consultations with employees) of employees of the City of Liberec and contributory organizations, various usable data were captured and processed on the territory of SO ORP Liberec. The aim of the work was to prove the usability of data from remote sensing in the state administration, which was proven because all the resulting data became part of the database of UAP and GIS departments and are used by Liberec City staff and contributory organizations.

The acquired data on surface temperature has served as a basis of the city's adaptation strategy for climate change and in public space manual. The data gained for the purposes of calculating vegetation indices have been used both for the same manual and for the city's green passport. The obtained water index data have been used to ascertain the location and area of water surfaces. These pieces of information have then been incorporated into the city's urban planning documentation. Other municipalities, both in the Czech Republic and abroad, can use the methodology described in this article for their own local agendas.

\section{ACKNOWLEDGEMENTS}

This work was supported by Project Number: UJEP-SGS-2019-44-001-3 (Spatial data remote sensing methods as a tool for modeling and observing the environment) covered by student grant competition at UJEP - Jan Evangelista Purkyně University in Ústí nad Labem.

\section{REFERENCES}

[1] AHMADI, S., Azarnivand, H., Khosravi, H., Dehghan, P., Behrang Manesh, M., 2019. Assessment the effect of drought and land use change on vegetation using Landsat data. Desert(2008-0875) 24, 2331.

[2] MACLACHLAN, A., Biggs, E., Roberts, G., Boruff, B., 2017. Urban Growth Dynamics in Perth, Western Australia: Using Applied Remote Sensing for Sustainable Future Planning. Land 6,9. https://doi.org/10.3390/land6010009

[3] MARCOF P., Statescu F., 2017. Comparasion of NDBI and NDVI as Indicators of SurfaceUrban Heat Island Effect in Landsat 8 Imagery: A Case Study of lasi. Present Environment and Sustainable Development 141. https://doi.org/10.1515/pesd-2017-0032

[4] MONDEJAR, J. P., Tongco, A. F., 2019. Near infrared band of Landsat 8 as water index: a case study around Cordova and Lapu-Lapu City, Cebu, Philippines. SustainableEnvironment Research 1. https://doi.org/10.1186/s42834-019-0016-5

[5] WONG, M.M.F., Fung, J.C.H., Yeung, P.P.S., 2019. High-resolution calculation of the urban vegetation fraction in the Pearl River Delta from the Sentinel-2 NDVI for urban climate model parameterization. Geosci. Lett. 6, 2. https://doi.org/10.1186/s40562-019-0132-4

[6] RADOUX, J., Chomé, G., Jacques, D.C., Waldner, F., Bellemans, N., Matton, N., Lamarche, C., d'Andrimont, R., Defourny, P., 2016. Sentinel-2's Potential for Sub-Pixel LandscapeFeature Detection. Remote Sensing 8, 488.

[7] KAPLAN, G., Avdan, U., Avdan, Z.Y., 2018. Urban Heat Island Analysis Using the Landsat8 Satellite Data: A Case Study in Skopje, Macedonia. Proceedings 2, 358. https://doi.org/10.3390/ecrs-205171

[8] ROUSE, J.W, Haas, R.H., Scheel, J.A., and Deering, D.W. (1974) 'Monitoring VegetationSystems 
in the Great Plains with ERTS.' Proceedings, 3rd Earth Resource Technology Satellite (ERTS) Symposium, vol. 1, p. 48-62.

[9] ZHA, Y., J. Gao a S. Ni. "Using the normalized index of difference created in the automaticmapping of urban areas from TM images." International Journal of Remote Sensing 24, no. 3 (2003): 583-594.

[10] McFEETERS, S. K., (1996) The use of the Normalized Difference Water Index (NDWI) in the delineation of open water features, International Journal of Remote Sensing, 17:7, 1425-1432,DOI: 10.1080/0143116960894871

[11] HAFIZI, H., KALKAN, K. Evaluation of Object-Based Water Body Extraction ApproachesUsing Landsat-8 Imagery. Journal of Aeronautics [online]. 2020, 13(1), 81-89 [cit. 2020-07-01]. ISSN 13040448. Available from:

http://search.ebscohost.com/login.aspx?direct=true\&db=a9h\&an=141501455\&scope=site 